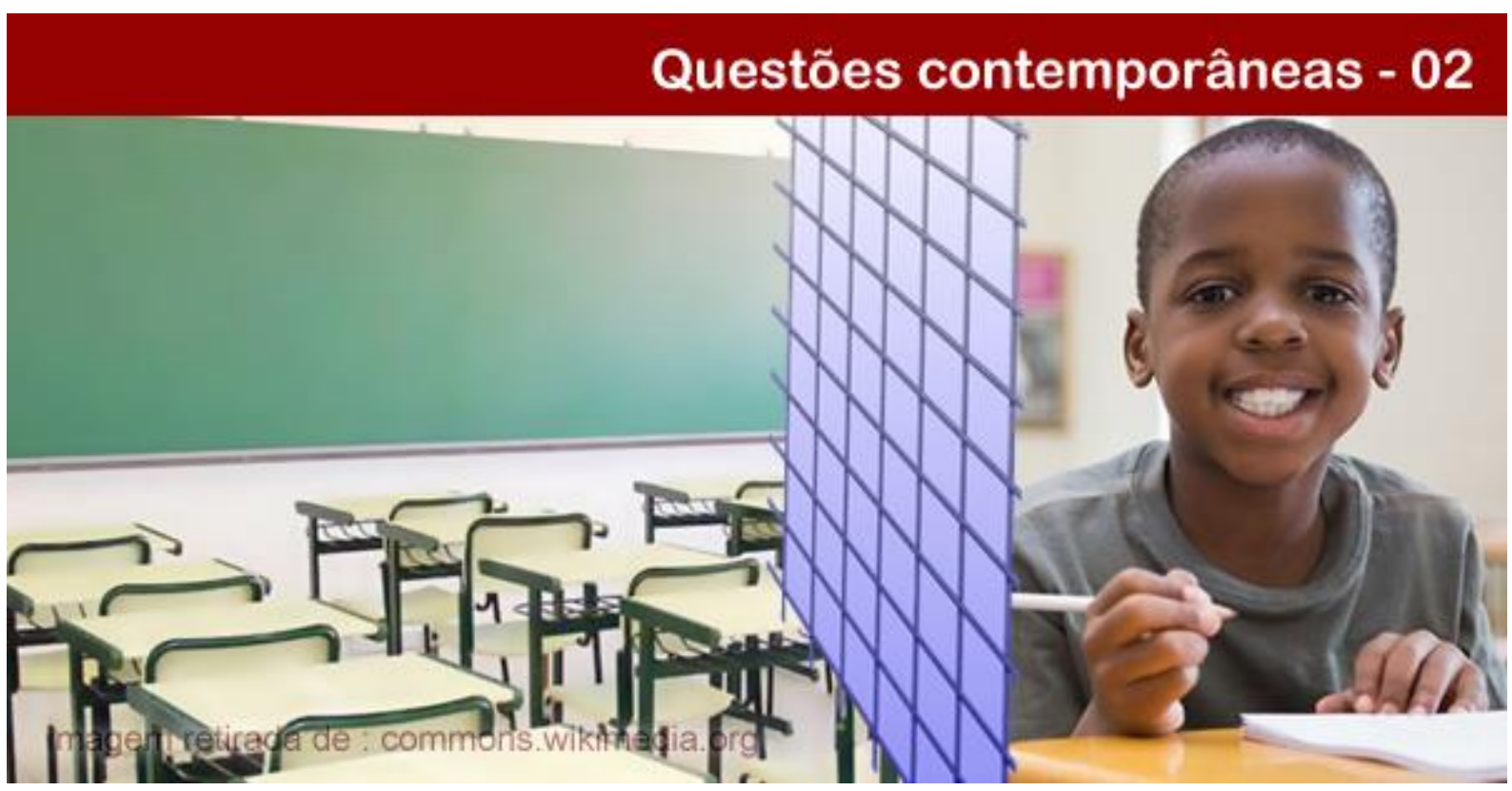

\title{
A ESCOLA EM UMA REALIDADE QUÂNTICA: EDUCAÇÃO E PARADIGMAS EMERGENTES ${ }^{1}$
}

\author{
Diogo Silveira Hereia y Antunes \\ Professor. Mestre em Educação pela Pontifícia Universidade Católica (PUC/RS). Especialista em Psicologia \\ Transpessoal pela Faculdade Spei (FACSPEI) e Residência Multiprofissional em Saúde da Família na \\ Universidade Federal do Rio Grande (FURG). Graduado em Educação Física pela Universidade Federal do Rio \\ Grande do Sul(UFRGS/2010).E-mail: diogoyantunes@gmail.com.
}

\section{Andreia Mendes dos Santos}

Psicóloga. Professora na Pontifícia Universidade Católica (PUC/RS). Doutora em Serviço Social pela PUC/RS. Coordenadora do Núcleo de Estudos e Pesquisa em Infância(s) e Educação Infantil. E-mail: andreia.mendes@pucrs.br.

Resumo: A emergência de paradigmas advindos de descobertas da física quântica, psicologia e biologia tem proporcionado novas formas de ver e interagir com o mundo, que rompem com o materialismo e a ciência moderna, perspectivas que ainda influenciam fortemente a sociedade contemporânea. Este artigo aborda a concepção de realidade fundamentada na teoria dos campos refletindo sobre as influências desta perspectiva na educação escolar. O método utilizado incluiu revisão da literatura, visitas técnicas em dez escolas no Brasil, Argentina e Uruguai que foram registradas em diários de campo - e entrevistas com coordenadoras, professoras e mães de duas das escolas visitadas. O conteúdo coletado foi avaliado a partir da análise de conteúdo, conforme Bardin e Minayo. Os resultados das visitas possibilitaram revelar aspectos relacionados ao modo de ser escola e suas aproximações com as características das escolas emergentes; somando-se às entrevistas, foi possível verificar que as escolas emergentes propõem novas possibilidades de ser escola. As conclusões apontam que, guardadas as devidas diferenças conceituais, há um conjunto de escolas que se pautam a partir dos paradigmas quânticos, denominadas aqui de escolas emergentes, já constituindo experiências concretas destas "novas" Kósmoslogias. Adotar estes preceitos possibilita a compreensão da multidimensionalidade humana, biológica, emocional, racional, intuitiva, social e cultural, além da inseparatividade de nossa existência e do mundo que nos rodeia. Permite, também, a adoção de práticas ainda pouco comuns nas escolas contemporâneas como o Yoga, meditação, danças circulares

\footnotetext{
${ }^{1}$ Este artigo foi elaborado a partir da dissertação de mestrado intitulada "Da inovação em educação às escolas emergentes: papel social, valores e estratégias para formação humana” (ANTUNES, 2018).
}

\section{POLÊM!CA $\mid$ LABORE (}

Polêmica - Revista Eletrônica da Uerj - Rua São Francisco Xavier, 524, $1^{\circ}$ andar bloco D, sl.1001 • Tels.: +55 21 2334-4088 / 4087 • http://www.e-publicacoes.uerj.br/index.php/polemica/index http://www.labore.uerj.br • laboreuerj@yahoo.com.br 
e psicodrama, além de convergir para que se assuma um posicionamento ético de respeito a todas as formas de vida e superação de qualquer forma de exploração e sectarismo.

Palavras-chave: Paradigmas. Escolas Emergentes. Física Quântica. Teoria dos Campos.

\title{
THE SCHOOL IN A QUANTUM REALITY: EDUCATION AND EMERGING PARADIGMS
}

\begin{abstract}
The emergence of paradigms arising from the discoveries of quantum physics, psychology and biology have provided new ways of seeing and interacting with the world that break with materialism and modern science, perspectives that still strongly influence contemporary society. This research approaches the concept of reality based on the field theory reflecting on the influences of this perspective in school education. The methodology used included review of the literature, technical visits in ten schools in Brazil, Argentina and Uruguay - which were recorded in field journals - and interviews of coordinators, teachers and mothers of two of the schools visited. The collected content was evaluated using the content analysis, according to Bardin and Minayo. The results of the visits made it possible to reveal aspects related to the way of being school and its approximations with the characteristics of the emerging schools; In addition to the interviews, it was possible to verify that emerging schools propose new possibilities for being a school. The conclusions point out that, with due regard for conceptual differences, there is a set of schools based on the quantum paradigms, referred to here as emerging schools, already being concrete experiences of these "new" Kósmoslogies. Adopting these precepts enables the understanding of human multidimensionality, biological, emotional, rational, intuitive, social and cultural, as well as the inseparability of our existence and the world around us. It allows the adoption of practices still uncommon in contemporary schools such as Yoga, meditation, circular dances and psychodrama, and still converges to assume an ethical position of respect for all forms of life and overcoming any form of exploitation and sectarianism.
\end{abstract}

Keywords: Paradigms. Emerging Schools. Quantum physics. Theory of Fields.

\section{Introdução}

A escola moderna surgiu em meados do século XV, na Europa, e seu desenvolvimento acompanhou a transição do pensamento mágico centrado na perspectiva do cristianismo para uma concepção pautada na ciência moderna. A emergência do paradigma clássico abriu espaço para novas formas de compreender e relacionar-se com o mundo, influenciando todas as instituições europeias e, com o fenômeno da colonização, culturas de todo o globo.

O surgimento da teoria quântica, em 1900, passou a ter maior influência sobre a sociedade, em meados dos anos 1950, e se acelerou, durante os anos 1980, trazendo à tona novas descobertas e perspectivas a respeito da concepção do universo e da realidade, permitindo que outros campos da ciência, como a psicologia transpessoal e a biologia, construíssem concepções alternativas a respeito da psique e da vida (RADIN, 2008; GROF, 2000; SHELDRAKE, 1993).

Na ciência contemporânea convivem, nem sempre de forma harmônica, três principais paradigmas: Moderno, Pós-Estruturalista e Emergente (DALLA ZEN, 2010). Este último, muito recentemente, começa a influenciar o campo da educação, manifestando-se em algumas

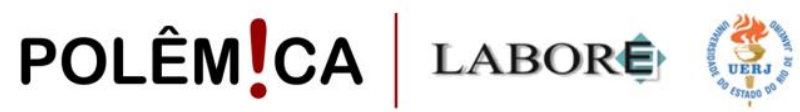

Polêmica - Revista Eletrônica da Uerj - Rua São Francisco Xavier, 524, $1^{\circ}$ andar

bloco D, sl.1001 • Tels.: +55 21 2334-4088/4087 • http://www.e-publicacoes.uerj.br/index.php/polemica/index

http://www.labore.uerj.br • laboreuerj@yahoo.com.br 
escolas que pautam seus modos de ser a partir de Kósmologias ${ }^{2}$ emergentes, sustentadas nas teorias quânticas e em descobertas de outros campos de vanguarda da ciência. A intenção deste artigo é debater a respeito da concepção da realidade, partindo da teoria dos campos, refletindo sobre a influência desta perspectiva na educação escolar. Esta teoria pressupõe que a realidade é composta não apenas de matéria, como afirma a ciência cartesiana, mas de um conjunto de campos não locais e não materiais que permeiam o tempo e o espaço (RADIN, 2008). Esta é uma das teorias contemporâneas que busca superar dilemas surgidos de experimentos científicos para explicar a constituição do Kósmos.

O estudo aqui apresentado é um recorte de dissertação de mestrado e caracterizou-se como pesquisa qualitativa, de caráter exploratório, integrou uma revisão da literatura, em especial nas áreas da física, psicologia transpessoal, biologia e educação, visitas técnicas realizadas em dez escolas no Brasil, Uruguai e Argentina, e entrevistas com coordenadoras, professoras e pais de duas destas escolas. É relevante colocar, que a pesquisa destinava-se a compreender o papel social, os valores e as estratégias para formação humana dessas escolas, mas em conjunto com estas temáticas, emergiram elementos que tinham tamanha afinidade com a teoria dos campos e suas contribuições para a educação, que decidimos aprofundá-lo e apresentá-los neste artigo.

As visitas técnicas realizadas tiveram o intuito de identificar os fundamentos filosóficos, epistemológicos e pedagógicos das escolas e selecionar as instituições onde seriam realizadas as entrevistas, levando em conta a radicalidade da experiência com relação à implementação de pedagogias pautadas nos paradigmas emergentes, o ineditismo e a abertura à pesquisa. Elas incluíram diálogos com o diretor ou um professor da escola, tiveram tempo médio de duas horas de duração e as observações realizadas foram registradas em diário de campo, onde foram anotadas impressões sobre fatos concretos, acontecimentos, relações e experiências pessoais do pesquisadores.

As entrevistas seguiram roteiro semiestruturado - que combinam perguntas abertas e fechadas, possibilitando ao informante a possibilidade de discorrer sobre o tema (BONI; QUARESMA, 2005) -, cujas questões norteadoras buscavam compreender a história, os pressupostos filosóficos, valores, práticas pedagógicas e papel social das escolas. As

\footnotetext{
${ }^{2} \mathrm{O}$ termo grego Kósmossignifica o "todo padronizado de toda a existência, incluindo os reinos físico, emocional, mental e espiritual. A realidade suprema, não meramente o cosmos ou dimensão física, [material]" (WILBER, 2000, p. 10).
}

\section{POLÊM!CA $\mid$ LABORE}

Polêmica - Revista Eletrônica da Uerj - Rua São Francisco Xavier, 524, $1^{\circ}$ andar 
informações coletadas, tanto nas entrevistas quanto nas visitas técnicas, foram analisadas a partir dos pressupostos de Bardin (1977) e Minayo (2004), utilizando-se a análise de conteúdo e organizando os achados em categorias.

Os achados resultantes das visitas técnicas possibilitaram revelar aspectos relacionados aos modos de ser escola e suas aproximações com as características das escolas emergentes, que serão apresentados ao se discutir outras visões e novas possibilidades de ser escola. Como resultados das entrevistas, foram construídas, ao total, dez categorias ${ }^{3}$, uma delas relacionavase a influência dos campos sutis na educação e motivou a apresentação desta pesquisa - de forma mais aprofundada e direta do que foi feito na escrita da dissertação que lhe dá origem, reflexos da educação ao se aceitar uma realidade quântica, uma vez que relaciona experiências vivenciadas na escola, em especial ligadas ao desenvolvimento humano integral e a perspectiva de realidade apresentada pela teoria dos campos.

\section{Outras visões, novas possibilidades de ser escola}

Kuhn (1992) afirma que, no seu uso estabelecido, um paradigma é um modelo ou padrão aceito, incluindo, ao mesmo tempo, lei, teoria, aplicação e instrumentação. Os paradigmas proporcionam modelos dos quais brotam as tradições da pesquisa científica. Assim, pessoas cuja pesquisa está baseada em paradigmas compartilhados estão comprometidas com as mesmas regras e padrões para a prática científica.

A sociedade ocidental tem seus modos de vida fortemente influenciados pelo paradigma Moderno, decorrente da associação de várias correntes de pensamento, dentre as quais se destacam a "Revolução Científica, o Iluminismo e a Revolução Industrial, que estiveram presentes a partir dos séculos XVII, XVIII e XIX” (MORAES, 1996, p. 5). O pensamento religioso medieval, na Europa, foi gradativamente perdendo espaço, na medida em que o Renascimento, as grandes navegações marítimas e o racionalismo se fortaleciam. Influenciada pela física e astronomia, através dos trabalhos de Copérnico, Galileu, Newton, Descartes, Bacon, constitui-se a compreensão do funcionamento do universo como uma máquina (MORAES, 1996).

\footnotetext{
${ }^{3}$ Valores; Estratégias para formação humana; O papel social das escolas emergentes; Desenvolvimento da criança (apontado como diferencial em relação a outras escolas); Desenvolvimento das crianças (apontado como em comum em relação a outras escolas); Transformações na família; Desafios e situações dilema (escola-alunosfamília); Estratégias de comunicação com as famílias / Relação com as famílias; Influência dos Campos sutis; Convívio "multissocial".
}

\section{POLÊM!CA $\mid$ LABORE}

Polêmica - Revista Eletrônica da Uerj - Rua São Francisco Xavier, 524, $1^{\circ}$ andar

bloco D, sl.1001 • Tels.: +55 21 2334-4088 / 4087 • http://www.e-publicacoes.uerj.br/index.php/polemica/index http://www.labore.uerj.br • laboreuerj@yahoo.com.br 
Ainda que a ciência moderna tenha nos dado a capacidade de manipular o mundo material e criar refinadas tecnologias, ela acabou por desintegrar o ser, a sociedade, a natureza e a própria dinâmica da vida (MORAES, 1996). A forma como temos lidado com a vida, a partir da influência do pensamento moderno, afastou o homem dos ciclos naturais. A crença no universo como uma máquina imprimiu sobre o mundo e nossas relações um funcionamento mecânico, ao mesmo tempo em que o ímpeto pelo desenvolvimento e o progresso, o antropocentrismo emergente do iluminismo, o patriarcado e o poder adquirido com as tecnologias pós-industriais levaram a uma relação predatória e exploratória com a terra e os seres que a habitam e nos desvincularam da dimensão sagrada da existência, essa ordem do mistério que é abordada pelas tradições de sabedoria que se voltam para o desenvolvimento da espiritualidade.

Precisamos de novos paradigmas que nos ajudem a ir além dos limites impostos pelo
pensamento reducionista e simplificador que nos impede de alçar novos voos em
busca de nossa sobrevivência e transcendência. Uma transcendência que sinaliza que
já é tempo de maior liberdade do espírito humano, tempo em que nenhuma
racionalidade científica será capaz de aprisionar a emoção, o sentimento e a
criatividade do ser humano em nome da objetividade que conspira contra a própria
inteireza (MORAES; DE LA TORRE, 2004, p. 23).

O esforço que vem sendo realizado por alguns pesquisadores ${ }^{4}$ na constituição de novas e mais abrangentes compreensões sobre o mundo, tem resultado no que Dalla Zen (2010) classifica como "paradigmas emergentes". Estas perspectivas surgem com a física quântica e têm sido reforçadas por uma ampla gama de pesquisas realizadas em diversas outras áreas do conhecimento, dentre as quais se destacam a biologia, a psicologia transpessoal, a filosofia e a antropologia (SHELDRAKE, 1993; KUSCH, 1999; NICOLESCU, 2005; GROF, 2000).

A biologia traz um novo olhar para os sistemas vivos e a recolocação dos seres humanos dentro da teia da vida, compreendendo e reconhecendo que há uma inteligência que rege os sistemas vivos, e que esta aponta em direção à ampliação da diversidade e complexidade de suas relações e que as regras que organizam a vida são, em um determinado nível de relações, as mesmas para todos os seres vivos (BUNYARD, 1996). Assim, ao invés do posicionamento como um agente privilegiado e dotado do direito de exploração e reorganização dos sistemas, a biologia reorienta nossa posição no ciclo da vida em um ponto que nos possibilita não apenas

\footnotetext{
${ }^{4}$ Entre eles podem ser citados: Basarab Nicolescu, Hubiratan D’Ambrosio, Amit Goswami, Ken Wilber, Roberto Crema, Pierre Weil, Rupert Sheldrake e Dean Radin.
}

\section{POLÊM!CA $\mid$ LABORE}


um compromisso de solidariedade com a humanidade, como já nos apontava Freire (1982), mas com todas as formas de vida, construindo relações mais harmoniosas, amorosas e colaborativas, conosco mesmo e com os outros seres.

A Psicologia Transpessoal reintegra a dimensão espiritual para uma compreensão mais ampliada do ser humano e de sua posição no Kósmos, ampliando-se o olhar da existência para um "eixo vertical" que incorpora a perspectiva "horizontal" da experiência da vida no planeta, integrando a ordem do mistério e a busca de um sentido mais profundo para a existência (GROF, 2000; POZATTI, 2007). A física quântica transforma a concepção materialista do Kósmos como uma máquina, em uma totalidade integrada em seus campos sutis e material, em uma estrutura, quem sabe, autoconsciente (GOSWAMI; REED; GOSWAMI, 2008). A nova física das possibilidades aponta como princípios deste paradigma:

\begin{abstract}
Monismo da Consciência: a existência integrada/entrelaçada de campos não materiais constitutivos da realidade; b) objetividade fraca: a realidade é constantemente formada a partir da interação entre sujeito e objeto, através do colapso das ondas de possibilidade; c) incerteza: não é possível medir a posição e a velocidade (momentum) de objetos quânticos simultaneamente e seus movimentos são indetermináveis matematicamente (por isso, a matemática quântica é probabilística e não determinista); d) não localidade: as interações entre os objetos não se dão apenas de forma local, mas também à distância, através de entrelaçamento de campos sutis e e) causalidade descendente: certos fenômenos são ocasionados por informações oriundas de outro "nível" de realidade, tais como a influência mente-matéria (GOSWAMI, REED, GOSWAMI, 2008).
\end{abstract}

Ainda a respeito dos paradigmas emergentes, Moraes e De La Torre, afirmam que

Subjacente às raízes dos pensamentos quântico e biológico, existem sementes epistemológicas capazes de fundamentarem o processo de construção do conhecimento, o desenvolvimento da aprendizagem, o conhecimento em rede, a autonomia e a criatividade. São sementes que podem influenciar o pensamento humano em direção a uma nova construção e reconstrução não apenas da educação, mas, sobretudo, a um melhor re-posicionamento do aprendiz/aprendente diante do mundo e da vida, a partir de uma compreensão mais adequada do que seja a realidade e o significado de sua própria humanidade. (MORAES; DE LA TORRE, 2004, p. 23).

Estes princípios são a base para uma compreensão da realidade mais coerente com sua complexidade e que se manifestam em um conjunto de escolas que pautam sua concepção da realidade, de sujeito, seus processos de trabalho e práticas educativas partindo dos conhecimentos sustentados por estes paradigmas.

\title{
POLÊM!CA $\mid$ LABORE
}

Polêmica - Revista Eletrônica da Uerj - Rua São Francisco Xavier, 524, $1^{\circ}$ andar

bloco D, sl.1001 • Tels.: +55 21 2334-4088/4087 • http://www.e-publicacoes.uerj.br/index.php/polemica/index

http://www.labore.uerj.br • laboreuerj@yahoo.com.br 
Então, se por um lado, a escola convencional, pautada no paradigma cartesiano, é marcada pela organização rígida dos tempos, pela arquitetura pouco ou nada acolhedora ${ }^{5}$, por estabelecer conteúdos a priori, ensinando-os da mesma forma a todos os alunos, muito centrada no desenvolvimento da racionalidade e da competitividade - utilizando métodos de ensino ainda centrados na "transmissão" de conhecimentos, pela divisão por idades e pelas formas autoritárias de lidar com a criança (BASTINI, 2000; BARRERA, 2016) -, por outro lado, as pesquisas realizadas por Moraes (1996) e da mesma autora com de La Torre (2004) e Vieira (2015) sobre escolas que se alicerçam sobre os paradigmas emergentes em educação permitiram constatar um conjunto de características que constituem um outro modo de ser escola, que denominamos escolas emergentes. Estas são: complexas - compreendem a interligação do eunós-natureza-espírito, na teia da vida; transdisciplinares - reconhecem a unidade do conhecimento e a complementaridade da ciência, tradições de sabedoria, filosofia e arte; multidimensionais - entendem o ser humano em suas dimensões biológica, emocional, racional, espiritual, individual e coletiva; interacionistas - o conhecimento se constrói nas relações e em espaços de segurança e afeto; processuais - mais focadas nos processos de aprendizado e produção de conhecimento do que na transmissão de conteúdos prontos; e éticas - centradas em valores de defesa e respeito à vida.

Estes princípios foram utilizados para balizar a análise das escolas visitadas. Importante ressaltar que estas características não são elementos rígidos e estanques, mas qualidades vivas e dinâmicas, que podem se manifestar em um gradiente de distintas maneiras e de diferentes intensidades, na lógica de compreensão de uma teia de relações e possibilidades de ser escola emergente. O conceito de gradiente firma-se a partir da compreensão de que não é possível estabelecer uma fronteira rígida, que marque uma secção entre "o convencional" e "o emergente", mas sim um continuum entre os padrões do "mais convencional" e as possibilidades "mais emergentes" nesta teia de conexões ligadas a cada um dos conceitos apontados.

Apresentamos a seguir uma síntese dos achados realizados nas escolas visitadas. Ainda que estas nem sempre explicitem claramente o conceito que aqui trazemos de paradigmas emergentes em educação, foi possível evidenciar, a partir das características das escolas

\footnotetext{
${ }^{5}$ Com portões e grades nas janelas, paredes de cores homogêneas, pés direito altos e uma estrutura imponente, com classes e cadeiras desconfortáveis e de tamanho inadequado, conferem uma estrutura de uma "grande instituição", distante de um ambiente "familiar e acolhedor" (BASTINI, 2000).
}

\section{POLÊM!CA $\mid$ LABORË}


observadas, suas correlações com os princípios que apontamos acima, que definem as escolas emergentes. As categorizamos então a partir de três possibilidades: a) apresentam fortes aproximações com os paradigmas emergentes; b) apresentam algumas aproximações; ou c) apresentam pouca aproximação.

a) Fortes aproximações:

- Escolas neo-humanista de educação infantil (Porto Alegre, RS, Brasil) ${ }^{6}$ : Apresenta uma concepção multidimensional e integrada da realidade e educação, com fortes e explícitas prerrogativas éticas. Alicerça-se sobre quatro pilares fundamentais: princípios Yama e Niyama ${ }^{7}$, prática da yoga, meditação e alimentação vegetariana. A escola adota uma pedagogia de projetos que compreende uma proposta de construção de conhecimento partindo dos interesses dos alunos.

- Escola Ayni (Guaporé, RS, Brasil) ${ }^{8}$ : Possui uma visão integradora, ética, transdisciplinar e complexa. Reconhece a multidimensionalidade humana, oferece contato intenso com a natureza e busca uma forte inserção e interação comunitária. Pedagogia baseada em projetos e processos de construção do conhecimento. Construiu sua pedagogia a partir de influências da Educação viva, Montessori, Escola da Ponte e Permacultura.

- Caminho do Meio (Viamão, RS, Brasil): Construiu uma proposta pedagógica transdisciplinar integrando princípios do Budismo Tibetano e pedagogia Waldorf. Com isso apresenta princípios éticos e estéticos, forte relação com a natureza e reconhecimento da multidimensionalidade humana. A descoberta do mundo interno é um elemento estruturador da pedagogia da escola.

- Amigos do Verde (Porto Alegre, RS, Brasil): Escola possui uma pedagogia transdisciplinar pautada no que denomina auto-eco-conhecimento, volta-se para desenvolver de forma integrada os aspectos cognitivos, afetivos, corporais, sociais e

\footnotetext{
${ }^{6}$ Duas escolas foram visitadas e, posteriormente, foram selecionadas para a realização das entrevistas.

7 YAMA: Ahimsa - Não violência; Satya - Verdade; Asteya - Não roubar; Brahmacarya - Amor Universal; Aparigraha - Vida simples; NIYAMA: Shaoca - Limpeza; IishvaraPranidhana - Confiar no fluxo da vida; Svadhyaya - praticar o autoconhecimento e desenvolvimento espiritual; Tapah - Solidariedade e realização de serviço planetário; Santósa - tranquilidade interior.

${ }^{8}$ Como estratégia de inserção comunitária, apesar de cumprir todas as prerrogativas legais para ser uma escola formal, esta organização funciona como "escola em turno inverso", em função de suas características decidimos mantê-la na análise.
}

\section{POLÊM!CA $\mid$ LABORE}

Polêmica - Revista Eletrônica da Uerj - Rua São Francisco Xavier, 524, $1^{\circ}$ andar

bloco D, sl.1001 • Tels.: +55 21 2334-4088/4087 • http://www.e-publicacoes.uerj.br/index.php/polemica/index http://www.labore.uerj.br • laboreuerj@yahoo.com.br 
ambientais. Com uma forte proposta de ligação com a natureza e agroecologia. O aprendizado é pautado em uma pedagogia de projetos e por relações éticas de respeito entre todos os seres.

b) Algumas aproximações:

- Escola neo-humanista de ensino fundamental (Porto Alegre, RS, Brasil): Tem como base os mesmos valores e pilares das escolas neo-humanistas de educação infantil, mas ainda divide os conteúdos em disciplinas, distanciando-se de perspectivas interacionistas e integradoras do conhecimento. Está estudando a possibilidade de adotar outros modelos pedagógicos como salas temáticas.

- WaldorfQuerência (Porto Alegre, RS, Brasil): Pautada nos princípios da Antroposofia, reconhece a multidimensionalidade humana a partir de dimensões que descrevem como físicas, anímicas e espirituais. Os conhecimentos ensinados para as crianças são organizados a priori, a partir de uma abordagem ligada características das fases da vida e trabalhados de forma integrada entre o intelecto, o corpo, arte e ritmo.

c) Poucas aproximações:

- Tierra del Sol (Tilcara, Jujuy, Argentina): Reconhece a subjetividade e afetividade, assim, além do desenvolvimento intelectual oferece uma formação artística através de atividades de teatro, música e artes plásticas. Pauta-se em uma perspectiva ética de respeito e solidariedade entre seus membros. Apresenta maiores afinidades com perspectivas paradigmáticas humanistas do que emergentes.

- Escuela Libre del Bosque (La Paloma, Rocha, Uruguai): Pautada no que denominam educação viva, aposta fortemente na autonomia e liberdade das crianças em sua possibilidade de escolha e no aprendizado construído a partir da experiência e convivência com os outros e a natureza. Reconhece a multidimensionalidade humana a partir de uma perspectiva de espiritualidade própria. Aproxima-se mais de abordagens radicais da escola nova ${ }^{9}$ do que dos paradigmas emergentes.

\footnotetext{
${ }^{9}$ Movimento que iniciou no final do século XIX, criticou fundamentalmente a concepção de infância e o método de trabalho da escola convencional, elaborou conceitos como "criança ativa" e "trabalho psicológico" (BASTINI, 2000).
}

\section{POLÊM!CA $\mid$ LABORE}


- Espaço Educativo Casa Amarela (Campo Largo, PR, Brasil) ${ }^{10}$ : Espaço que reúne famílias que optaram pela educação domiciliar, visando à troca de experiências e convivência para fomentar a construção de aprendizados conjuntos. Tem influência da educação viva e oferece a seus membros amplo contato com a natureza e práticas para o desenvolvimento humano integral. Assim como a instituição anterior, apresenta-se mais próxima dos princípios de abordagens radicais da escola nova do que dos paradigmas emergentes.

Entendemos que assumir uma perspectiva emergente na escola (assim como na economia, religião, família, mídia ou gestão dos coletivos humanos) é um firme posicionamento político-epistemológico que parte de valores e Kósmologias não sectárias que defendem a vida e transcendem os paradigmas hegemônicos que transitam, em geral, entre os conflitos de uma "direita" neoliberal e uma "esquerda" materialista-dialética. Tampouco é, nesta lógica, um posicionamento de "centro", ou se coloca em um relativismo pós-moderno. É um ponto integrador, fora da linha deste "bastão dual", que tem sido construído através da integração entre os conhecimentos da ciência de vanguarda e da acumulação histórica da sabedoria de antigas tradições; aplica-se sobre todos os campos da vida humana com a intenção de construir possibilidades de bem viver ${ }^{11}$ e já se manifesta em algumas experiências humanas como nas escolas citadas anteriormente.

\section{Educação em uma realidade quântica}

Após as visitas às escolas, selecionamos duas delas para aprofundamento do estudo, levando em conta a radicalidade da experiência com relação à implementação de pedagogias pautadas nos paradigmas emergentes, o ineditismo e a abertura à pesquisa. As entrevistas realizadas nas escolas de educação infantil neo-humanistas permitiram a emergência de informações que apontam como a pedagogia destas organizações busca um desenvolvimento humano integral. Além disso, elas permitiram evidenciar fortes entrecruzamentos entre a

\footnotetext{
${ }^{10}$ Apesar desta instituição caracterizar-se como um espaço não escolar, pois englobava famílias que adotaram a educação domiciliar, por suas características, optamos por mantê-la em nossa análise.

${ }^{11}$ Este termo, advindo dos povos originários da América (Suma Kawsay - do quéchua suma: bem, kawsay: viver), expressa o modo de viver, organização social e econômica de suas culturas, que emerge na contemporaneidade, como alternativa ao conceito de desenvolvimento e como possibilidade de transcendência ao capitalismo e socialismo. Foi integrado às constituições do Equador, em 2008, e Bolívia, em 2009 (CHAMORRO, 2017).
}

\section{POLÊM!CA $\mid$ LABORE}


proposta pedagógica destas escolas e a literatura sobre a teoria dos campos, elemento sobre o qual iremos discorrer agora.

A compreensão a respeito da constituição Kósmica e da condição humana oriundas dos Paradigmas Emergentes desconstrói a ideia materialista de que o universo é uma máquina composta apenas por matéria, propondo que a Consciência, Kósmos ou Totalidade ${ }^{12}$ é formada pela integração dos seguintes campos: material, vital, mental e supramental (GOSWAMI, REED, GOSWAMI, 2008). A vida e toda a experiência humana se dão na relação com estes campos de experiência, dos quais fazemos parte como parte da Totalidade. Assim, ao mesmo tempo em que a Consciência é o Kósmos, somos Consciência, como um fractal, uma parte, que representa um todo.

Enquanto humanos, somos capazes de perceber cada um destes campos, através das funções da consciência estudadas por Jung. O campo material é explorado através das sensações vivenciadas por nosso corpo biológico (tato, olfato, paladar, visão e audição); o campo vital, por meio de nossas emoções; o mental, por meio do pensamento; o supramental, por meio de nossa intuição; e a Consciência é conectada por meio da Transcendência (GOSWAMI, 2009).

De acordo com os conceitos da física quântica, estes campos constitutivos da realidade estão entrelaçados, interagindo de forma conectada, ou, em outras palavras, interligados de forma não local e transtemporal. Formam um continuum que liga todo o universo, que transcende a compreensão moderna de tempo e espaço lineares. Esta perspectiva complexa e sistêmica, que compreende a inter-relação de todos os elementos do universo vivenciado pelos sujeitos, em suas relações consigo mesmo, com os outros seres, com o planeta e com a Consciência, possibilita uma forma radicalmente diferente de compreensão do ser humano e, por consequência, abre caminho para novas formas de educar. Veremos em mais detalhes cada um desses campos com os quais nos relacionamos em nossa existência, entrecruzando a teoria dos campos e achados que emergiram nas visitas e entrevistas, evidenciando algumas contribuições para educação, em especial, de como estas dimensões do ser humano são trabalhadas nas escolas emergentes. É preciso ter a compreensão de que não são elementos

\footnotetext{
${ }^{12}$ Goswami (2009) conceitua a Consciência (com maiúscula), como o fundamento do Ser, o observado, o elemento original, autossuficiente e constitutivo de todas as coisas. Kósmos, termo grego utilizado por WILBER (2000, p. 10) e Totalidade são os conceitos usados por Pozatti (2007), e, ainda que haja algumas distinções na compreensão de cada um destes autores, são encontradas inúmeras convergências em suas obras.
}

\section{POLÊM!CA $\mid$ LABORE}


isolados e que a divisão apresentada aqui ao explicá-los um a um é um recurso didático para facilitar o entendimento a respeito dos mesmos.

\section{Campo material}

Este campo envolve nosso corpo biológico e tudo que nos rodeia e que percebemos com os nossos sentidos e tem sido largamente estudado pela ciência, que investe grande parte de suas pesquisas e tecnologias sobre ele. Experimentamos o campo material por meio de nosso corpo biológico, formado pelos diversos sistemas (muscular, ósseo, respiratório, circulatório etc.), através das sensações (visão, audição, olfato, tato e paladar) (GOSWAMI, 2009).

Sua compreensão não carece de grandes explicações, pois é de fácil percepção. No entanto, há algumas reflexões a respeito deste campo que são significativas para a educação. $\mathrm{O}$ corpo biológico, campo de estudo da cultura corporal do movimento humano, deveria colocarse na escola através da experiência da dança, jogos, ginástica, práticas corporais integrativas, lutas e esportes. A reflexão a seguir aponta a relação da escola moderna com as práticas corporais:

\footnotetext{
Nas escolas de nosso tempo o corpo considerado como res extensa permanece passivo. Enfim, o corpo não vai à escola. (2) As principais correntes epistemológicas sobre a origem do conhecimento, da mesma forma, limitam-se a expressões de um conhecimento predominantemente racional. O corpo permanece ausente de interesse epistemológico. (3) Uma pedagogia que se limita ao exclusivamente racional é míope e, por consequência, não pode exigir configurar-se numa pedagogia da complexidade. É necessário recolocar os corpos na epistemologia, na pedagogia e nas escolas. É a reinvenção dos corpos (GAYA, 2006, p. 251).
}

O autor defende uma reinvenção dos corpos em uma pedagogia da complexidade que integre as experiências educativas ao corpo biológico, emoções e racionalidade. A pedagogia defendida pelo autor e presente nas escolas emergentes, pode ser observada a partir de algumas experiências propostas, por exemplo, pelas escolas neo-humanistas, na medida em que dão importância às vivências corporais dos alunos, garantindo vivências diárias ligadas ao movimento e integrando práticas pouco usuais na escola, tais como trocas de massagem, danças circulares e danças da paz ou Yoga. Para exemplificar esta questão, coloco a fala de uma das mães entrevistadas em uma escola neo-humanista de educação infantil:

Eles deitam no chão e ficam fazendo escultura e coisa com o próprio corpo, ela adora isso ai também, deita em tudo quanto é canto [risos] é bastante coisa. [...] brincadeiras que ninguém mais brinca, pega-pega, cabra cega, isso ela chega em casa, falando,

\section{POLÊM!CA $\mid$ LABORE}

Polêmica - Revista Eletrônica da Uerj - Rua São Francisco Xavier, 524, $1^{\circ}$ andar

bloco D, sl.1001 • Tels.: +55 21 2334-4088/4087 • http://www.e-publicacoes.uerj.br/index.php/polemica/index

http://www.labore.uerj.br • laboreuerj@yahoo.com.br 
cantando, cantar elas cantam todo o dia, eles fazem Yoga. Que mais eles têm...Tinta, tinta ela quer só brincar, brincam bastante com giz, giz de cera, eles cantam, dançam, que mais que ela faz, em casa, estou pensando agora, não me lembro mais, ela faz tanta coisa... (Nashira ${ }^{13}$, 09/05/2017).

Uma questão fundamental a respeito do campo material é que o que acreditávamos ser separado de nós (o externo, o outro), está, na realidade, intimamente entrelaçado conosco (o interno, o eu). Este entrelaçamento pode ser observado a partir do resultado de algumas pesquisas realizadas com rigorosa metodologia. Em uma delas, relatada por Dean Radin (2008), buscava encontrar se havia relação entre sensações viscerais e emoções detectadas à distância. A pesquisa envolveu 26 pares de adultos que já se conheciam como amigos ou parceiros de longa data, utilizando o seguinte procedimento: um transmissor sentava-se em uma sala com dois monitores e fones de ouvido. Em intervalos aleatórios, um dos monitores mostrava a imagem do receptor, que estava sentado em outra sala, sem qualquer tipo de comunicação. $\mathrm{O}$ outro monitor mostrava sequências de imagens emocionais (positivas, de raiva ou medo) ou neutras, e, ao mesmo tempo, tocava músicas cujo ritmo se conectava com a qualidade emocional das imagens. Os dois indivíduos estavam sendo monitorados por Eletrogastrograma (EGG), aparelho semelhante ao utilizado para a realização de eletroencefalograma, mas que mede a eletrofisiologia do estômago, órgão que tem grande correlação com estados emocionais. Os resultados demonstram que as respostas do Eletrogastrograma do receptor eram mais amplas quando o transmissor experimentava emoções positivas ou tristes do que quando passava por períodos emocionalmente neutros. Estes resultados, assim como de outras pesquisas semelhantes, indicam que há fortes evidências para aceitarmos que há correlações entre nossas sensações viscerais e sentimentos com estados emocionais de outras pessoas, mesmo distantes.

Os efeitos destes fenômenos não locais de entrelaçamento são pouco ou nada observados no campo da educação e carecem de mais atenção. Esta compreensão do entrelaçamento não local do campo material e de outros campos traz ao debate a importância do clima emocional, a ambiência, a estética e a relação com a natureza a partir de um caráter muito mais profundo, uma vez que passamos a compreender que há a possibilidade de uma conexão profunda entre os indivíduos e destes com o meio onde estão, o que pode influenciar seu estado de saúde e aprendizado.

${ }^{13}$ Os nomes dos entrevistados foram substituído por nomes fictícios.

\section{POLÊM!CA $\mid$ LABORE}


Outro aspecto importante relacionado ao corpo biológico e à educação encontra-se em sua interconexão com os Estados Ampliados de Consciência ${ }^{14}$, que são estados de percepção distintos do estado de vigília, onde ocorrem alterações qualitativas nos padrões psíquicos de funcionamento e percepção da realidade e que permitem a emergência de uma série de experiências capazes de proporcionar profundos insights psicológicos relativos à história pessoal do sujeito, dificuldades emocionais, problemas interpessoais, questões filosóficas, metafísicas e espirituais. A dança, o controle da respiração, o canto, o jejum, são práticas que facilitam acesso a estes estados incomuns de percepção (GROF, 2000), "que podem ser utilizados na educação, no desenvolvimento da criatividade, para o despertar da sabedoria interior de cada ser humano" (REICHOW, 2002, p. 105).

\section{Campo Vital}

O campo vital há milênios vem sendo estudado pelas antigas tradições de sabedoria, encontrando termos para denominá-lo em línguas originárias da América, África, Europa e Ásia. As medicinas orientais, tal como a Ayurveda ou a Medicina Tradicional Chinesa, desenvolveram mapas e tecnologias terapêuticas para atuar sobre este campo. Seus "movimentos" geram o que percebemos como sentimentos, que são o domínio dos campos morfogenéticos, onde se encontram as informações relativas à forma e ao funcionamento dos órgãos (GOSWAMI, 2009).

Há uma questão chave neste domínio, apontada por Casassus (2007). Buscando identificar que fatores interferem na aprendizagem em diversos países da América Latina, o pesquisador analisou mais de trinta variáveis, como condições de trabalho, salário, experiência e formação dos professores, o número de livros em casa e na biblioteca, o tempo que os pais passam diariamente com os filhos e o total de alunos por classe. Os resultados indicaram que o clima emocional adequado dentro da sala teve uma importância maior do que todos os demais fatores somados. Nas instituições em que os alunos se dão bem com os colegas, não há brigas, o relacionamento harmonioso predomina e não há interrupções nas aulas, eles se saem melhor. Verificou-se que, nestes casos, o desempenho chegou a ser superior em $36 \%$ na nota média da prova de Linguagem e em $46 \%$ na de Matemática.

${ }^{14}$ Estes estados podem ser verificados pela alteração das ondas cerebrais identificados por eletroencefalograma. As ondas Beta se manifestam em estado de vigília. Alfa e Theta no estado de sonho. Delta em sono profundo ou durante a experiência de acessar estados ampliados de consciência em sujeitos despertos (TREVISOL, 2008).

\section{POLÊM!CA $\mid$ LABORE.}

Polêmica - Revista Eletrônica da Uerj - Rua São Francisco Xavier, 524, $1^{\circ}$ andar

bloco D, sl.1001 • Tels.: +55 21 2334-4088 / 4087 • http://www.e-publicacoes.uerj.br/index.php/polemica/index http://www.labore.uerj.br • laboreuerj@yahoo.com.br 
Com relação a este ponto, o relato de uma professora de educação infantil de uma escola neo-humanista reflete a respeito dos valores e de algumas práticas adotadas pela escola e como estes elementos influenciam no estado emocional da turma:

\begin{abstract}
Entra no dia a dia da gente, o com licença, desculpa, não bater, o carinho, a compreensão, a paciência, então no maternalzinho. Como eles são menores, a gente conta muita história, fazemos... como vou dizer... a gente faz Yoga, a gente faz meditação. Daí eles vão se acalmando naquilo ali, quando eles estão muito agitados a gente diz, vamos fazer uma meditação, colocamos os colchonetes no chão, baixamos as cortinas, colocamos uma música beeem baixinha aí eles já vão relaxando, ficam mais calmos sabe? A gente também, então a gente passa para eles e acaba ficando na gente também, e isso é bom em outras escolas eu não tinha isso antes. (Maia, 09/05/2017).
\end{abstract}

Um elemento importante que conecta o campo vital às reflexões anteriores a respeito do ambiente é a percepção de que todos os seres vivos possuem em si uma dinâmica vital, e que interagem na medida em que os seres se relacionam. Tal percepção traz à tona a importância da conexão com a natureza e da utilização deste elemento nas dinâmicas educacionais. O mundo natural possui um ritmo orgânico e uma lógica sistêmica aos quais estivemos integrados em nossa existência enquanto humanidade, até um período muito recente, quando, com o iluminismo, a revolução industrial e o desenvolvimento urbano, passamos a uma condição que intenta a separação do humano e do natural, apostando em um ritmo acelerado e uma visão fragmentada. O confinamento em espaços concretados segrega os aprendizes da possibilidade de experienciar esta relação com a dinâmica vital de outros seres e de aprender através de sua própria experiência as leis que regem a vida.

Estudos demonstram a correlação entre os estados de saúde dos sujeitos e a relação com a natureza, o que indica a importância da relação com outros seres, como plantas e microorganismos consorciados a estas, para a manutenção de nosso equilíbrio vital. A presença de plantas pode criar um ecossistema que atua na filtragem do ar, melhorando sua qualidade, além de que talvez contribuam para o aumento da umidade do ar e para a diminuição dos níveis de poeira (FJELD; BONNEVIE, 2002), além de serem capazes de reduzir o stress (ULRICH; PARSONS, 1992).

Retomando a concepção da dinâmica vital e da influência não local sobre os seres humanos, há uma pesquisa interessante que evidencia os efeitos da não localidade nas relações sociais. Hagelin et al. (1999) desenvolveram uma pesquisa com meditação em Washington, Estados Unidos. Aproximadamente, 4.000 pessoas participaram dos grupos de meditação

\title{
POLÊM!CA $\mid$ LABORE
}

Polêmica - Revista Eletrônica da Uerj - Rua São Francisco Xavier, 524, $1^{\circ}$ andar

bloco D, sl.1001 • Tels.: +55 21 2334-4088 / 4087 • http://www.e-publicacoes.uerj.br/index.php/polemica/index

http://www.labore.uerj.br • laboreuerj@yahoo.com.br 
espalhados na cidade, e o que se observou, com relação a dados dos anos anteriores, foi uma diminuição de $15,6 \%$ nos crimes violentos, chegando a um pico de $23 \%$ de queda, que coincidiu com o período em que havia mais sujeitos meditando. Não houve qualquer outro fator ambiental ou social ao qual pudesse ter sido atribuída esta queda. Este estudo indica a possibilidade da criação de uma "atmosfera-psi", que influencie o comportamento humano a partir da focalização da dinâmica emocional e mental de grupos de indivíduos. A possível existência deste campo de "influência" gerado pela inter-relação das dinâmicas emocionais e intenção mental dos indivíduos que compõem determinado grupo levanta a necessidade de uma discussão deste tema em espaços educacionais em um patamar muito mais aprofundado do que sequer temos imaginado quando nos referimos às relações humanas e relação professor-alunos. A respeito deste ponto, trago a fala da coordenadora de uma escola neo-humanista que exprime algumas de suas percepções:

\begin{abstract}
A gente trabalha... eu acho que essa energia, na verdade, de forma positiva. Vai muito do trabalho grupal mesmo, das pessoas comprarem essa proposta e estarem aqui de coração. Eu acho que tudo ajuda para que esta energia esteja fluindo de certa forma, no ambiente de trabalho. [...] E eu acho muito positivo ver outros profissionais, e eles sempre trazem que as nossas crianças são diferentes das outras escolas. [...] Não que as nossas crianças não tragam agitação, elas são crianças normais, com movimento, mas é bem positivo isso que os outros profissionais às vezes trazem, de que sentem uma energia diferente dentro do nosso espaço. (Adhara, 23/05/2017).
\end{abstract}

Além da fala da diretora, diversos professores relataram um clima de cooperação e harmonia na escola, que se estabelece entre os professores e corpo diretivo, estendendo-se à relação com as crianças e suas famílias - não que não haja conflitos, mas indicam uma dinâmica relacional que se direciona a relações de parceria e se pauta no diálogo e respeito mútuo.

\title{
Campo Mental
}

A mente é o campo dos pensamentos, os quais nos permitem atribuir significados ao mundo (GOSWAMI, 2009). É importante ressaltar que a ciência materialista entende a mente como estando localizada no cérebro, fenômeno que é posto em xeque a partir dos resultados de algumas pesquisas. Estudos que analisam a correlação da atividade mental de pares à distância, na qual eram semelhantes os sinais observados por eletroencefalograma em dois sujeitos separados e sem comunicação, ao passo que apenas um deles recebia algum tipo de estímulo, demonstram a existência de algum tipo de conexão mental, agindo de forma não local (RADIN,

\section{POLÊM!CA $\mid$ LABORE}

Polêmica - Revista Eletrônica da Uerj - Rua São Francisco Xavier, 524, $1^{\circ}$ andar

bloco D, sl.1001 • Tels.: +55 21 2334-4088 / 4087 • http://www.e-publicacoes.uerj.br/index.php/polemica/index

http://www.labore.uerj.br • laboreuerj@yahoo.com.br 
2008). Outra pesquisa nesta área foi publicada na revista Science, em 1980, e citada por Radin (2008) e por Lipton (2007), na qual um rapaz com hidrocefalia tinha uma massa encefálica insignificante, mas possuía um QI acima da média, trabalhava e se relacionava. Estas e outras questões levam a crer que a mente é um campo sutil, cujas informações podem ser acessadas por nós e que tem o cérebro como um órgão "correlato" no corpo biológico (GOSWAMI, 2009).

Algumas pesquisas indicam, ainda, a formação de uma espécie de campo mental coletivo que pode, inclusive, influenciara matéria. Talvez a principal pesquisa que demonstre tal efeito seja a do "Projeto de Consciência Global", que constatou que em eventos como o 11 de Setembro, ou a morte da princesa Diana, houve um desvio muito significativo nas sequências geradas por geradores de números aleatórios espalhados pelo mundo. Os pesquisadores, minuciosamente, questionaram as razões para tal efeito (erro nas máquinas, erro estatístico etc.) e chegaram à conclusão de que a focalização de milhares de espectadores ao mesmo tempo em um determinado elemento gera um padrão de coerência que influencia estes aparelhos (RADIN, 2008).

A focalização da atenção em determinado sentido pode influenciar não só elementos que ocorrem simultaneamente no presente, mas, também, eventos do passado. Leibovici (2001) buscou analisar o efeito da oração através do tempo. Para tal, realizou uma pesquisa envolvendo todos os 3.393 pacientes internados com septicemia, de 1990 a 1996, num hospital israelense. O autor desenvolveu o estudo, no ano 2000, separando os pacientes aleatoriamente em um grupo que recebia orações e um grupo controle. Para cada paciente do primeiro grupo, foi realizada uma breve reza que pedia a recuperação do paciente e do grupo inteiro. A febre de pacientes que haviam recebido alta há pelo menos quatro anos foi significativamente menor e a mortalidade foi de forma pouco significativa menor no grupo que recebeu oração, comparado ao grupo controle.

Esses resultados remetem à discussão sobre o efeito da focalização da atenção, no caso, através da oração e meditação, incluindo elementos que transcendem o tempo e o espaço, o que reforça a possibilidade de que não só o espaço está conectado, mas também o passado e o futuro estão interligados ao presente. O efeito relatado neste estudo evidencia o que, na física, tem-se chamado de "escolha retardada"15 (GOSWAMI, 2009).

\footnotetext{
${ }^{15}$ Quando uma escolha ocorrida "no presente" interfere em acontecimentos "do passado".

\section{POLÊM!CA $\mid$ LABORE}


A ciência moderna, alicerçada no materialismo, tem negado todo tipo de fenômeno como estes, associando-os a misticismo, erro metodológico ou má intenção dos pesquisadores. Esta postura dogmática e preconceituosa tem-nos impedido de observar e estudar uma série de fenômenos da realidade, levando-nos a sermos incapazes de, por hora, compreendermos de forma mais aprofundada os impactos desta nova percepção acerca da realidade no campo da educação.

\section{Campo Supramental}

De acordo com o físico Amit Goswami (2006, 2009), para que algo exista tanto em nível mental, como vital e material, é necessário um "projeto" (programas ou leis) que rejam o seu funcionamento. Esta informação, segundo o autor, encontra-se no campo Supramental. De todos os campos expostos até agora, este, certamente, é o de mais difícil compreensão. É um campo sutil, de difícil apreensão por meio da experimentação científica e, enquanto vivência humana na sociedade ocidental contemporânea, temos pouca consciência dele. Ainda que nos influencie constantemente, isto se dá, de maneira geral, de forma inconsciente.

As informações que nos indicam sua existência partem de perspectivas teóricas, dentro da física quântica, que buscam resolver paradoxos encontrados na ciência (GOSWAMI, REED, GOSWAMI, 2008), dos estudos da psicologia transpessoal e junguiana e de diversas tradições de sabedoria, cujos sujeitos relatam experiências que não podem ser relacionadas com os níveis material, vital ou mental. Este campo é chamado também de dimensão transpessoal ou espiritual. Conectamo-nos com as informações contidas nele por meio da função da consciência da intuição, que nos proporciona vivenciar insights, sonhos e experiências profundas em estados incomuns de consciência (GOSWAMI, 2009; POZATTI, 2007).

Talvez a forma mais fácil de compreendê-lo seja observando-o por meio da psicologia. Jung (2000) cunhou o termo inconsciente coletivo, que possui conteúdos e modos de comportamento que apresentam semelhanças em toda parte e em todos os indivíduos. Em outras palavras, "são [elementos] idênticos em todos os seres humanos, constituindo, portanto, um substrato psíquico comum, de natureza psíquica suprapessoal, que existe em cada indivíduo" (JUNG, 2001, p. 15). Os conteúdos do inconsciente coletivo são chamados arquétipos. Estes conteúdos estudados por Jung são as "leis", ou padrões de possibilidade que regem os modos de comportamento humanos.

\section{POLÊM!CA $\mid$ LABORE}


A possibilidade de acessar "novos" arquétipos, ou seja, novas possibilidades de ser, pode trazer profundas transformações para os indivíduos em sua relação consigo, com os outros e com a vida, sendo muitas vezes um "salto" de uma condição desarmônica, de conflito interior ou exterior, para uma nova forma de viver em maior harmonia e mais madura. Reichow (2002) realizou sua pesquisa de mestrado a respeito da significação de Estados Ampliados de Consciência com crianças em uma escola pública de Porto Alegre. O autor utilizou mandalas como linguagem para expressão das significações produzidas durante as experiências com estados ampliados de consciência. Estas permitiram observar que símbolos do inconsciente coletivo emergiram durante as vivências, o que reiterou que existe dentro de cada ser humano uma fonte de sabedoria que está para além dos limites da personalidade.

\section{Consciência}

A Consciência representa a Totalidade do Universo, é a unidade onde se manifestam de forma integrada os outros quatro campos. Não há dualidade mente-matéria, como proposto pelo Dualismo, nem troca de energia entre elas. Todos estes elementos (campo material, vital, mental e supramental) são diferentes possibilidades do Kósmos que interagem de forma não local. Dentro da ciência, esta perspectiva tem sido defendida pelo físico Amit Goswami (2009) e, guardadas algumas diferenças teóricas, outros pesquisadores tem apresentado teorias bastante semelhantes (WILBER, 2000, 2004; LASZLO, 2008; MCTAGGART, 2008).

Enquanto experiência humana é pouco comum acessar o nível de consciência de dissolução da dualidade e compreensão da Totalidade, mas há alguns relatos na história sobre sujeitos como Buda ou Cristo que tiveram tal experiência. Entretanto, aqui, de fato, interessa perceber este "quinto elemento" como um aspecto integrador e transcendente. Primeiro, ele permite nos reconhecermos como parte do Universo, deslocando a humanidade da arrogância do antropocentrismo moderno e do vazio existencial do mecanicismo. Passamos a nos perceber como elementos integrados aos sistemas vivos e ao Kósmos como um todo. Segundo, ele reconhece o desenvolvimento humano como processo dinâmico em direção à ampliação de nossa percepção sobre nós mesmos e a realidade, com o reconhecimento de nossa humanidade e da possibilidade de buscarmos inteireza e harmonia, mesmo em meio aos nossos desafios cotidianos. A integração destes dois elementos permite a reinvenção de nossa condição humana na busca de superação do sofrimento, da exploração, da violência, através da manifestação de

\section{POLÊM!CA $\mid$ LABORE}


modos de viver mais amorosos e igualitários, uma vez que nos percebemos parte do Kósmos e membros de uma comunidade planetária.

\section{Considerações finais}

A concepção acerca da realidade apresentada nesta pesquisa não é um consenso no campo da ciência. A coexistência dos paradigmas apresentados no início desse debate leva a conflitos conceituais-políticos-práticos no território da vida. Mesmo dentro dos paradigmas emergentes podemos encontrar, para além da teoria dos campos apresentada aqui, teorias: da "mente coletiva", multidimensionais e de espaço tempo, além de diferentes teorias da mecânica quântica. Mas neste debate, a perspectiva adotada nesta pesquisa apresenta soluções coerentes para alguns paradoxos observados em pesquisas como as citadas no decorrer do texto e possibilita uma ampliação de nossa compreensão a respeito do Kósmos e da experiência humana.

Um dos achados relevantes desta pesquisa, a partir das visitas realizadas nas escolas, consiste em ter revelado a existência de organizações educativas alicerçadas em fundamentos e práticas que encontram respaldo na teoria dos campos. Este elemento denota a viabilidade de uma educação pautada em visões de vanguarda da ciência que têm se constituído nos paradigmas emergentes. Mesmo que por vezes essas escolas não se refiram diretamente a esta teoria, os conceitos apresentados encontram afinidades fortíssimas com os princípios apresentados aqui.

Evidenciou-se, também, que uma das contribuições importantes da teoria dos campos na educação é o reconhecimento claro e detalhado da multidimensionalidade humana em seus aspectos individuais e coletivos, permitindo, por exemplo, adotar a utilização de diversas práticas para o desenvolvimento integral do ser humano, transcendendo o "treinamento racional" da escola convencional e a separatividade mente-corpo. Através das informações que emergiram, especialmente, nas entrevistas, pudemos compreendera importância das práticas corporais, não só para o desenvolvimento dos aspectos biológicos, mas das emoções, matemática e das relações humanas. $O$ desenvolvimento da inteligência emocional e da harmonia do campo vital põe em evidência a relevância de dinâmicas de grupo como o psicodrama e de práticas do Yoga, como pranayamas e asanas ou Tai Chi, conhecidas historicamente como terapêuticas do campo vital, que trazem benefícios também ao corpo

\section{POLÊM!CA $\mid$ LABORE}


biológico e mental. Danças circulares, trocas de massagem e outras práticas que fomentem vínculos humanos afetivos e sensíveis, ganham espaço, sem excluir a importância do indivíduo, transcendendo uma educação individualista centrada nos resultados de cada aluno e adotando uma concepção equilibrada do eu e o nós. Práticas como a meditação ganham relevância por sua influência positiva nas emoções e nos padrões mentais individuais, mas também na influência coletiva de criar um ambiente de harmonia e paz. O desenvolvimento dos conhecimentos historicamente adquiridos pela humanidade é realizado a partir de experiências e de conexões com a realidade dos alunos, em processos de coconstrução. O acesso a estados ampliados de consciência é reconhecido como recurso pedagógico que podem aprofundara compreensão dos indivíduos sobre si mesmos e o mundo, afirmando uma educação voltada não só ao conhecimento do exterior, mas também à interiorização e ao autoconhecimento. Para além das novas estratégias para formação humana que passam a ser adotadas em uma perspectiva emergente, oriundas de sua visão multidimensional, a recolocação do ser humano como parte integrada e inseparável dos sistemas vivos evoca um posicionamento ético de respeito e colaboração com todas as formas de vida do planeta Terra.

\section{Referências}

ANTUNES, Diogo Silveira Heredia y. Da inovação em educação às escolas emergentes: papel social, valores e estratégias para formação humana. 2018. 168 f. Dissertação (Mestrado em Educação) - Programa de PósGraduação em Educação, Pontifícia Universidade Católica do Rio Grande do Sul, Porto Alegre, 2018.

BARDIN, Laurence. Análise de conteúdo. Lisboa: Edições 70, 1977.

BARRERA, Tathyana Gouvêa Da Silva. O Movimento Brasileiro de Renovação Educacional no início do Século XXI. 2016. 276 f. Tese (Doutorado em Educação) - Faculdade de Educação da Universidade de São Paulo, São Paulo, 2016.

BASTINI, Mara Lúcia. Escola Alternativa: pedagogia da participação. Florianópolis: Cidade Futura, 2000.

BONI, Valdete; QUARESMA, Sílvia Jurema. Aprendendo a entrevistar: como fazer entrevistas em Ciências Sociais. Revista Eletrônica dos Pós-Graduandos em Sociologia Política da UFSC, v. 2, n. 1 (3), p. 68-80, jan./jul., 2005. Disponível em:〈https://periodicos.ufsc.br/index.php/emtese/article/viewFile/18027/16976>. Acesso em: 30 dez. 2018.

BUNYARD, Peter (Org.). Gaia in Action: Science of the living Earth. Edinburgh: Floris Books, 1996.

CASASSUS, Juan. A escola e a desigualdade. 2.ed. Brasília: Líber livro editora, UNESCO, 2007.

CHAMORRO, Graciela. Bem Viver nos povos indígenas. CEBI Virtual. Disponível em:<http://cebivirtual.com.br/ava/arquivos/FT1-M1.pdf>. Acesso em:12 dez. 2017.

\section{POLÊM!CA $\mid$ LABORE}


DALLA ZEN, Ana Maria. A crise de paradigmas e a ressignificação do conhecimento para o século XXI. Em Questão, Porto Alegre, v. 16, n.2, p. 49-63, jul./dez. 2010.

FJELD, Tove; BONNEVIE, Charite. The effect of plants and artificial day-light on the well-being and health of office workers, school children and health care personnel. Relatório do Seminário Floriade: reducing health complaints at work plants for people. Int. hort. exhib.p.1-10 Haarlemmermeer: 2002. Disponível em: <https://pdfs.semanticscholar.org/0c53/abbc781c2fc14b49c5b4ffaf7297aa33326b.pdf>. Acesso em: 14 de jun. 2017.

FREIRE, Paulo. Educação e mudança. São Paulo: Paz e Terra, 1982.

GAYA, Adroaldo. A reinvenção dos corpos: por uma pedagogia da complexidade. Sociologias, Porto Alegre, ano 8, n.15, p. 250-272, jan./jun. 2006.DOI: http://dx.doi.org/10.1590/S1517-45222006000100009. Disponível em: <http://www.scielo.br/pdf/soc/n15/a09v8n15.pdf>. Acesso em: 12 jun. 2017.

GOSWAMI, Amit. Evolução Criativa das Espécies: uma resposta da nova ciência para as limitações da teoria de Darwin. Tradução de Marcelo Borges. São Paulo: Aleph, 2009.

O Médico Quântico: Orientações de um físico para a saúde e a cura. Tradução de Euclides Luiz Calloni e Cleusa Margô Wosgrau. São Paulo: Cultrix, 2006.

GOSWAMI, Amit; REED, Richard; GOSWAMI, Maggie. O Universo autoconsciente: como a consciência cria o mundo material. Tradução de Ruy Jungmann. 2. ed. São Paulo: Aleph, 2008.

GROF, Stanislav. Psicologia do Futuro: lições da pesquisa moderna da consciência. Tradução de Jussara de Avellar Serpa. Niterói: Heresis, 2000.

HAGELIN, John Samuel et al. Effects of Group Practice of the Transcendental Meditation Program on Preventing Violent Crime in Washington, DC: Results of the National Demonstration Project. Social Indicators Research, v. 47, n. 2, p. 153-201, jun. 1999. Disponível em: <http://link.springer.com/article/10.1023\%2FA\%3A1006978911496\#page-1>. Acesso em: 12 jul. 2013.

JUNG, Carl Gustav. O Eu e o inconsciente. Tradução de Dora Maria Ferreira da Silva. 15. ed. Petrópolis: Vozes, 2001.

Os Arquétipos e o Inconsciente Coletivo. Tradução de Maria Luíza Appy, Dora Mariana R. Ferreira da Silva. Petrópolis: Vozes, 2000.

KUHN, Thomas Samuel. A estrutura das revoluções científicas. Tradução de Beatriz Vianna Boeira e Nelson Boeira. 3. ed. São Paulo: Perspectiva, 1992.

KUSCH, Rodolfo. América Profunda. 1. ed. Buenos Aires: Biblios, 1999.

LASZLO, Ervin. A Ciência e o Campo Akáshico: uma Teoria Integral de Tudo. São Paulo: Cultrix, 2008.

LIPTON, B. H. A Biologia da Crença: ciência e espiritualidade na mesma sintonia - o poder da consciência sobre a matéria e os milagres. São Paulo: Butterfly, 2007.

LEIBOVICI, Leonard. Effects of remote retroactive intercessory prayer on outcomes in pacients with bloodstream infection: randomised controlled Trial. BMJ, n. 323, p. 1450-1451, dez. 2001. Disponível em: <http://www.bmj.com/content/323/7327/1450>. Acesso em: 5 abr. 2013.

MCTAGGART, Lynne. O Campo: Em busca da força secreta do universo. Tradução de Claudia Gerpe Duarte. Rio de Janeiro: Rocco, 2008.

\section{POLÊM!CA $\mid$ LABORE}

Polêmica - Revista Eletrônica da Uerj - Rua São Francisco Xavier, 524, $1^{\circ}$ andar

bloco D, sl.1001 • Tels.: +55 21 2334-4088/4087 • http://www.e-publicacoes.uerj.br/index.php/polemica/index

http://www.labore.uerj.br • laboreuerj@yahoo.com.br 
MINAYO, Maria Cecília de Souza (ORG.) et al. Pesquisa social: Teoria método e Criatividade. 23. ed. Petrópolis: Editora Vozes, 2004.

MORAES, Maria Cândida. O paradigma educacional emergente: implicações na formação do professor e nas práticas pedagógicas. Em Aberto, Brasília, ano 16, n. 70, abr./jun. 1996. Disponível em:

<http://www.emaberto.inep.gov.br/index.php/emaberto/article/viewFile/2081/2050>. Acesso em: 24 out. 2017.

MORAES, Maria Cândida; DE LA TORRE, Saturnino. Sentipensar: Fundamentos e estratégias para reencantar a educação. Petrópolis: Vozes, 2004.

NICOLESCU, Basarab. O Manifesto da Transdisciplinaridade. Tradução de Lucia Pereira Souza. 3. ed. São Paulo: Triom, 2005.

POZATTI, Mauro Luiz. Buscando a inteireza do Ser: Proposições para o desenvolvimento sustentável da consciência humana. Porto Alegre: Gênese, 2007.

RADIN, Dean. Mentes Interligadas: evidências científicas da telepatia, da clarividência e de outros fenômenos psíquicos. São Paulo: Aleph, 2008.

REICHOW, Jeverson Rogério Costa. Processos de significação em estados ampliados de consciência dentro de uma abordagem transdisciplinar holística: estudo de caso com crianças de uma escola pública de Porto Alegre. 2002. Dissertação (Mestrado em Educação) - Programa de Pós-Graduação em Educação, Universidade Federal do Rio Grande do Sul, Porto Alegre, 2002.

SHELDRAKE, Rupert. O renascimento da natureza: o reflorescimento da ciência e de Deus. São Paulo: Cultrix, 1993.

TREVISOL, Jorge. Educação Transpessoal: Um jeito de educar a partir da interioridade. São Paulo: Paulinas, 2008.

VIEIRA, Adriano José Hertzog. MORAES, Maria Cândida. A docência no paradigma educacional emergente. EDUCERE, XII congresso nacional de educação. PUCPR, 26 a 29 de out. 2015. Disponível em: <http://educere.bruc.com.br/arquivo/pdf2015/16288_8237.pdf>. Acesso em: 24 out. 2017.

ULRICH,R. S. PARSONS, R. Influences of passive experiences with plants on individual well-being and health. In: RELF,D. (ed.). The Role of Horticulture in Human Well-Being and Social Development: A National Symposium. 1992, Portland. Anais [...] Portland: Timber Press, 1992, p. 93-105.

WILBER, Ken. Uma breve história do Universo: de Buda a Freud - religião e psicologia unidas pela primeira vez. Rio de Janeiro: Editora Nova Era, 2004.

Uma Teoria de Tudo: uma visão integral para os negócios, a política, a ciência e a espiritualidade. São Paulo: Cultrix, 2000.

Recebido em: 13/08/2018

Aceito em: 30/12/2018.

\section{POLÊM!CA LABORE}

Polêmica - Revista Eletrônica da Uerj - Rua São Francisco Xavier, 524, $1^{\circ}$ andar

bloco D, sl.1001 • Tels.: +55 21 2334-4088/4087 • http://www.e-publicacoes.uerj.br/index.php/polemica/index

http://www.labore.uerj.br • laboreuerj@yahoo.com.br 